\title{
Radiation therapy for Graves' ophthalmopathy: a systematic review and meta-analysis of randomized controlled trials
}

\author{
Radioterapia para oftalmopatia de Graves: uma revisão sistemática e meta-análise de \\ ensaios clínicos randomizados e controlados
}

Gustavo Arruda Viani ${ }^{1}$, André Campiolo Boin², Ligia Issa De Fendi ${ }^{3}$, Ellen Carrara Fonseca ${ }^{3}$, Eduardo Jose Stefano ${ }^{1}$, Jayter Silva de Paula ${ }^{4}$

\begin{abstract}
Purpose: To evaluate the efficacy of radiotherapy (RT) with total dose of $20 \mathrm{~Gy}$ (RT 20 Gy) in the treatment of Graves' ophthalmopathy.

Methods: A systematic review and meta-analysis of randomized controlled trials was performed comparing RT 20 Gy with or without glucocorticoid to clinical treatments for Graves' ophthalmopathy. The MEDLINE, EMBASE, Cochrane Library databases and recent relevant journals were searched. Relevant reports were reviewed by two reviewers. Response to radiotherapy was defined as clinical success according to each trial. We also evaluated the quality of life and whether RT to produce fewer side effects than other treatments.

Results: A total of 8 randomized controlled trials (439 patients) were identified. In the subgroup analysis, the overall response to treatment rates was better for: RT 20 Gy plus glucocorticoid vs glucocorticoids alone, OR=17.5 (C195\% 1.85-250, $\mathrm{p}=0.04)$, RT 20 Gy vs sham RT, OR=3.15 (Cl95\%1.59-6.23, $\mathrm{p}=0.003)$ and $R T$ 20 Gy plus intravenous glucocorticoid vs RT 20Gy plus oral glucocorticoid, OR=4.15(CI95\% 1.34-12.87, $p=0.01$ ). There were no differences between RT 20 Gy versus other fractionations and RT 20 Gy versus glucocorticoid alone. RT 20 Gy with or without glucocorticoids showed an improvement in diplopia grade, visual acuity, optic neuropathy, lid width, proptosis and ocular motility. No difference was seen for costs, intraocular pressure and quality of life.

Conclusion: Our data have shown that RT 20 Gy should be offered as a valid therapeutic option to patients with moderate to severe ophthalmopathy. The effectiveness of orbital radiotherapy can be increased by the synergistic interaction with glucocorticoids. Moreover, RT $20 \mathrm{~Gy}$ is useful to improve a lot of ocular symptoms, excluding intraocular pressure, without any difference in quality of life and costs.
\end{abstract}

Keywords: Graves ophthalmopathy; Exophthalmos; Radiotherapy; Meta-analysis, Review

\section{RESUMO}

Objetivo: Avaliar a eficácia da radioterapia (RT) com dose total de 20 Gy (RT 20 Gy) no tratamento da oftalmopatia de Graves.

Métodos: Uma revisão sistemática e meta-análise de ensaios clínicos randomizados foram realizadas comparando RT $20 \mathrm{~Gy}$, com ou sem glicocorticoides a tratamentos clinicos para a oftalmopatia de Graves. O MEDLINE, EMBASE, bases de dados da Biblioteca Cochrane e recentes de revistas relevantes foram pesquisados. Relatórios relevantes foram revisados por dois revisores. A resposta à radioterapia foi definida através do sucesso clinico de acordo a cada ensaio clínico. Nós também avaliamos a qualidade de vida e se a radioterapia produzia menos efeitos colaterais comparados a outras intervenções.

Resultados: Um total de 8 ensaios clínicos randomizados (439 pacientes) foram identificados. Na análise de subgrupo, a resposta global para as taxas de tratamento fol melhor para: RT 20 Gy além de glicocorticoides vs glicocorticoides sozinhos, $O R=17,5$ (IC95\% 1,85-250, p=0,04), RT 20 Gy vs sham RT, OR=3,15 (IC95\% 1,59-6,23, p=0,003) e RT 20 Gy além de glicocorticoides porvia intravenosa RT 20 Gy além de glicocorticoides orais, $O R=4,15$ (IC95\% 1,34-12,87, $p=0,01$ ). Não houve diferenças entre RT 20 Gy contra outros fracionamentos e 20 Gy RT contra glicocorticoides sozinhos. RT $20 \mathrm{~Gy}$, com ou sem glicocorticoides mostraram uma melhoria no grau de diplopia, acuidade visual, neuropatia óptica, abertura palpebral, proptose e da motilidade ocular. Não foi observada diferença para os custos, a pressão intraocular e a qualidade de vida. Conclusão: Nossos dados mostraram que 20 Gy RT deveser oferecida como uma opção terapêutica válida para pacientes com moderada a severa oftalmopatia de Graves. A eficácia da radioterapia orbital pode ser aumentada pela interação sinérgica com os glicocorticoides. Além disso, RT 20 Gy é útil para melhorar vários sintomas oculares, excluindo a pressão intraocular, sem qualquer diferença de qualidade de vida.

Descritores: Oftalmopatia de Graves; Exoftalmia; Radioterapia; Meta-análise, Revisão

\section{INTRODUCTION}

Graves' ophthalmopathy is a debilitating disease impairing the quality of life of the affected individuals. Despite recent progress in the understanding of its pathogenesis, treatment is often not satisfactory. In mild cases, local therapeutic measures (artificial tears and ointments, sunglasses, nocturnal eyes taping, prisms) can control symptoms and signs. In severe forms of the disease, aggressive measures are required. The management strategy for moderate tosevere Graves' ophthalmopathy is controversial. Systemic steroids are often effective ${ }^{(1-4)}$, but relapse is common when they are tapered or withdrawn ${ }^{(5)}$. A number of retrospective studies have reported the efficacy of orbital irradiation ${ }^{(6,7)}$ but prospective studies have shown conflicting results ${ }^{(8-10)}$. Some investigators have suggested that steroids provide excellent improvement in orbital inflammation in the short term, whereas the effects of orbital irradiation take longer to appear ${ }^{(11)}$. Studies that have compared combination therapy of orbital irradiation and systemic steroids with steroids alone therapy have produced conflicting results ${ }^{(12-18)}$. The accomplishment of a systematic review is the best manner for describing the state of our knowledge, and hence becomes the best way of obtaining high quality scientific evidence. Consequently, this systematic review was proposed to analyze the results from clinical trials that compared radiotherapy to any other treatment.
Submitted for publication: February 6, 2012

Accepted for publication: August 27, 2012

Study carried out at Faculty of Medicine of Marília, Department of Radiation Oncology.

Physician, Radiation Oncology Department, Escola de Medicina de Marília, Marília (SP), Brazil.

Medical Student, Escola de Medicina de Marília, Marília (SP), Brazil.

Department of Ophthalmology, Escola de Medicina de Marília, Marília (SP), Brazil.

Physician, Department of Ophthalmology, Escola de Medicina de Ribeirão Preto, Universidade de

São Paulo - USP - Ribeirão Preto (SP), Brazil.
Funding: No specific financial support was available for this study.

Disclosure of potential conflicts of interest: G.A.Viani, None; A.C.Boin, None; L.I.De Fendi, None; E.C.Fonseca, None; E.J.Stefano, None; J.S.de Paula, None.

Correspondence address: Gustavo Arruda Viani. Rua Coronel José Brás, 205/72 - Marília (SP) 17501-570 - Brazil - E-mail-gusviani@gmail.com 


\section{METHODS}

\section{TYPES OF STUDIES}

This systematic review properly included randomized controlled clinical trials. Any trial including only patients with mild Graves ophthalmopathy (GO), or any trial including patients with moderate-severe GO were included. The participants of studies included patients with $\mathrm{GO}$ diagnosis for the first time, not resistant to previous treatment and with no age limit. The intervention criteria to be included in this review was any trial in which radiotherapy with total dose of 20 Gy associated or not to glucocorticoid (of any kind) was the primary treatment compared to radiotherapy (RT) with total dose different of $20 \mathrm{~Gy}$, no radiotherapy or any another treatment. The efficacy of radiotherapy was evaluated following measures after treatment. The lid width was measured as the widest vertical dimension, proptosis was measured by an exophthalmometer, ocular motion was measured in degrees or constancy of diplopia, intraocular pressure measured using an applanation tonometer, optic nerve function was assessed by recording of the corrected visual acuity or fundoscopy. Response to radiotherapy was defined as clinical success according to each trial. We also evaluated the quality of life and whether RT produced fewer side effects than other treatments. Medline and manual searches were done (completed independently and in duplicate) to identify all published (manuscripts and abstracts) randomized controlled trials (RCTs) that compared radiotherapy for GO to any treatment. The Medline search was done between 1966 and 2006 with no language restrictions, using the search terms "ophthalmopathy," orbitopathy" and "Graves' ophthalmopathy," "radiotherapy" or "orbital radiotherapy," and "retro ocular radiotherapy". The second search was done through EMBASE and the Cochrane Library to identify randomized trials published between January 1998 and July 2006, using MeSH headings (ophthalmopathy, orbipathy, Graves' ophthalmopathy, orbital radiotherapy, retro ocular radiotherapy /sc \{Secondary\}, ex-lode Clinical Trials, clinical trial \{publication type\}) and text words (retro ocular radiotherapy radiotherapy, Graves' ophthalmopathy, trial, and study) without language restrictions. All the searched abstracts were screened for relevance. Manual searches were done by reviewing articles and abstracts cited in the reference lists of identified RCTs, by reviewing the first author's article, abstract file, from reference lists of retrieved papers, textbooks and review articles. Hand searches were carried out in the following journals between January Ophthalmology; Lancet; Ophthalmology; International Journal of Radiation Oncology, Biology, and Physics; and Journal of Clinical endocrinology and metabolism. Reference lists from identified studies and other relevant publications were scrutinized. Colleagues, collaborators, and other experts were contacted about ongoing and unpublished trials. From the titles and abstracts, relevant RCTs were identified. Two independent reviewers (V.A.G., A.C.B.) then assessed the RCTs to establish if predetermined inclusion criteria were met. Study suitableness was assessed using QUOROM criteria ${ }^{(19)}$. The RCTS were also independently assessed for quality according to predetermined criteria (method of randomization, blinding, statistical methods, quality of life assessment, data completeness, follow-up), and the data extracted and tabulated. Discrepancies between the two reviewers were resolved by discussion. The intention was to carry out a meta-analysis of outcomes if there were enough trials of sufficient quality and homogeneity.

\section{Statistics}

The efficacy of radiotherapy treatment with total dose of $20 \mathrm{~Gy}$ was measured through the response to treatment described in each trial. Responders to treatment were defined as patients who presented overall response to radiotherapy or other treatment, according to clinical success defined according to each trial. The data analyses were made with Review Manager Version 5.1 provided by The Cochrane Collaboration. All analyses were carried out on an intention to treat basis; that is, all patients randomly assigned to a treatment group were included in the analyses according to the assigned treatment, irrespective of whether they received the treatment or were excluded from analysis by the investigators. For categorical variables, weighted risk ratios and their 95\% confidence interval were calculated using RevMan 5.1 software according to the Peto method ${ }^{(20)}$. Results were tested for heterogeneity at significance level of $P<0.05$ according to the methods outlined by Der Simonian and Laird ${ }^{(21)}$. A fixed effects model was used if there was no evidence of heterogeneity between studies, if there was evidence of heterogeneity random effects model was used for meta-analysis.

The odds ratio and 95\% confidence interval were calculated for each trial and presented in a Forrest plot. Sensitivity analyses was performed by excluding the trials which Jadad-scale was only 1 score. Publication bias is a common concern in meta-analysis that is related to the tendency of journals to favor the publication of large and positive studies. We chose a commonly used method for detecting publication bias, which is a graphical plot of estimates of the ORs from the individual studies versus the inverse of their variances, which is commonly referred to as a "funnel plot." An asymmetry in the funnel would be expected if there was publication bias with smaller studies tending to show larger ORs, because small studies with no significant statistical results would be less likely to be reported.

\section{RESULTS}

\section{Study ChARACTERISTICS}

A total of 359 studies of treatment of $\mathrm{GO}$ were identified, from which we excluded those that did not involve the use of RT, thus limiting the selection to 22 studies. Of these only 8 were controlled clinical studies. Fourteen studies were excluded due to lack of original data, insufficient data for analysis, lack of randomization and/or retrospective design, no control group, earlier reports on individual studies. A total of 8 studies were included in this review ${ }^{(8-10,12-16)}$, as demonstrated in the figure 1. Study characteristics are shown in table 1. The studies were clearly heterogeneous, so we divided them into six groups:

A. 1 randomized studies (15 patients) that assessed the efficacy and safety of combined orbital irradiation and systemic steroids in the management of moderate-to-severe Graves' ophthalmopathy ${ }^{(16)}$.

B. 3 studies (190 patients) tested the efficacy of external beam irradiation compared with sham-irradiation ${ }^{(9,10,15)}$.

C. 1 study (82 patients) assessed the efficacy and safety of orbital radiotherapy combined with either oral glucocorticoid or iv glucocorticoids ${ }^{(14)}$.

D. 1 study (66 patients) compared the efficacy and tolerability of three RT protocols ${ }^{(12)}$.

E. 1 study (56 patients) evaluated the efficacy of combined therapy RT plus systemic methylprednisolone or systemic methylprednisolone alone.

F. 1 study (30 patients) compared the efficacy of combined therapy RT plus systemic glucocorticoids plus and radiotherapy alone ${ }^{(13)}$.

The studies had a randomized design with 209 patients submitted to RT with or without glucocorticoids and 230 patients submitted to other treatment $(9,10,12-16)$. The parameters evaluated in these studies were: Quality of life, costs, proptosis, visual acuity, diplopia, intraocular pressure, optic neuropathy, ocular motility and clinical response. Seven studies included in this review tested the efficacy of RT 20 Gy to improve proptosis $(9,10,12,14-16)$. However, only in the study performed by Marcocci et al., ${ }^{(14)}$ there was significant difference between the two modalities of treatment. Five studies investigated the lid width ${ }^{(9,10,12,14,15)}$ again Marcocci et al., ${ }^{(14)}$ was the only study to demonstrate significant difference. The visual acuity was evaluated in 


\section{9 potentially eligible abstracts from}
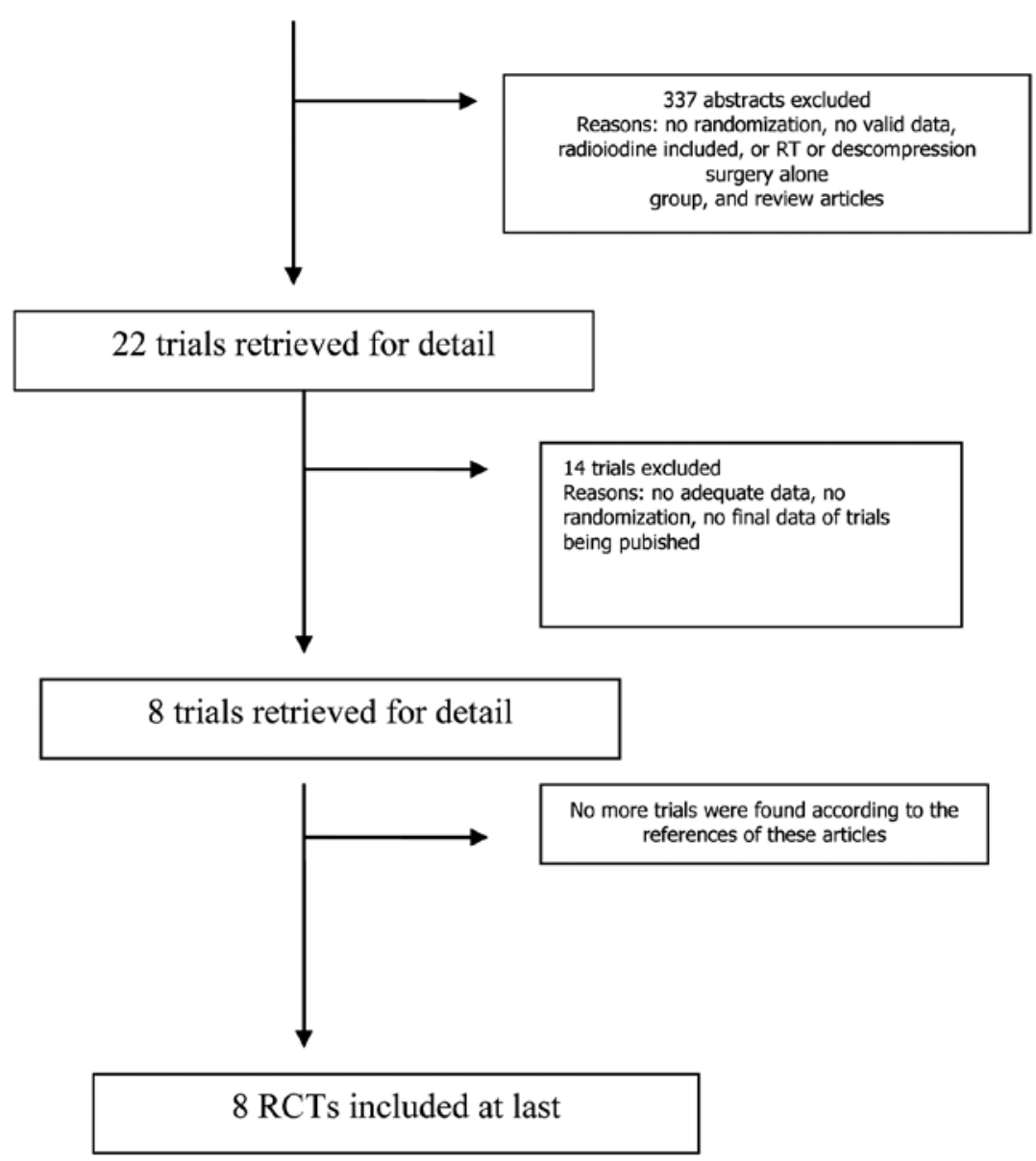

$\mathrm{RT}$ : radiation therapy; $\mathrm{RCT}$ : randomized controlled trial.

Figure 1. Flowchart according to QUOROM statement criteria.

three RCTs, ${ }^{(12,13,16)}$ only one trial ${ }^{(13)}$ showed benefit for RT 20 Gy arms. Diplopia was assessed in five RCTs $s^{(9,10,12,14,15)}$ of these studies Prummel et al., (15) and Mourits et al. ${ }^{\left({ }^{(9)}\right.}$ founded significant differences between radiotherapy versus sham radiotherapy for changes in diplopia, in the other studies it was not seen. Intraocular pressure was tested in two $\mathrm{RCTs}{ }^{(12,16)}$, one performed by $\mathrm{Ng}$ et al. ${ }^{(16)}$, and another by Kahaly et al. ${ }^{(12)}$, in both studies no benefit was seen in combined orbital irradiation and systemic steroids or using low dose of radiotherapy. Marcocci et al. ${ }^{(14)}$, was the only trial to assess the efficacy of radiotherapy to improve optic neuropathy. In this study combined orbital irradiation and systemic steroids were associated with significant difference to improve optic neuropathy.

Ocular motility and clinical response was tested in all RCTs $s^{(8-10,12-16)}$. RT 20 Gy with or without glucocorticoid achieved significant statistical difference in five of the eight trials evaluated for clinical response. Ocular motility was improved in six trials $s^{(8,9,13-16)}$ comparing RT 20 Gy with other treatments. Table 2 summarizes the parameters evaluated and the treatment results. According to the Jadad criteria, we assessed the quality of the randomized and comparative trials with regard to: a) method of randomization, b) treatment allocation, c) similarity between groups, d) specification of eligible criteria, e) blinded outcome of assessor, care provider and patient ${ }^{(22)}$. Applying these criteria made clear that the quality of the trials was high, as showed in the table 3 which describes in details the trials design, aim, study question, results, and conclusions.

\section{RESPONSE TO TREATMENT}

All the studies reported response to treatment as one of the outcomes. The criterions for evaluation of the response to treatment were heterogeneous between the trials. Altogether, the analyses included 8 trials with 439 patients ${ }^{(9,10,12-16)}$. The individual odds ratios ranged from 0.87 to 17.5 with a pooled odds ratio for all of the trials of 2.14 with a $95 \%$ confidence interval of 1.44 to 3.18 . The test for heterogeneity was not statistically significant with $p$ value 0.14 , which indicates that the pooling of the data was valid. The overall odds ratio suggests that there is difference between RT 20 Gy arms and other treatments in terms of response to treatment rate with p value 0.0002 , as shown in the figure 2 .

\section{RADIOTHERAPY VERSUS SHAM RADIOTHERAPY}

Three trials $s^{(9,10,15)}$ with 190 patients evaluated response to treatment comparing radiotherapy versus sham radiotherapy. The individual odds ratios ranged from 1 to 3.5 with a pooled odds ratio for all of the trials of 3.15 with a $95 \%$ confidence interval of 1.59 to 6.23. The test for heterogeneity was not statistically significant with $p$ value 0.28 , which indicates that the pooling of the data was valid. 
Table 1. Characteristics of the patients, parameters of the treatment, status of GO and end points of the studies included in this meta-analysis

\begin{tabular}{|c|c|c|c|c|c|}
\hline Trial (year) & $\begin{array}{l}\text { Patients/ } \\
\text { treatment }\end{array}$ & Diagnostic & $\begin{array}{l}\text { Status GO/treatment } \\
\text { hypertireoidism }\end{array}$ & $\begin{array}{c}\text { Equipament } \\
\text { Dose/angle/field }\end{array}$ & End point \\
\hline $\begin{array}{l}\text { Prummel et al., } \\
\text { (2004) }\end{array}$ & $\begin{array}{l}88 \\
\text { RT: } 44 \\
\text { NO RT: } 44\end{array}$ & $\begin{array}{l}\text { Signs and symptoms with } \\
\text { enlarged extraocular eye muscles on } \\
\text { coronal computed tomography scan } \\
\text { of the orbits }\end{array}$ & $\begin{array}{l}\text { Mild, antithyroid drugs, } \\
\text { TSH supression }\end{array}$ & $\begin{array}{l}\text { Linear accelerator/ } \\
20 \mathrm{~Gy} / 3 \text { grade anterior/ } \\
5 \times 5 \mathrm{~cm}\end{array}$ & $\begin{array}{l}\text { After } 12 \text { months, motility in } \\
\text { degrees, } \\
\text { proptosis, lid aperture, } \\
\text { diplopia, quality life, cost }\end{array}$ \\
\hline $\begin{array}{l}\text { Marcocci et al., } \\
(2001)\end{array}$ & $\begin{array}{l}82 \\
\text { RT+IVGC:41 } \\
\text { RT+ORGC: } 41\end{array}$ & $\begin{array}{l}\text { Signs and symptoms with enlarged } \\
\text { extraocular eye muscles on coronal } \\
\text { computed tomography scan of the } \\
\text { orbits }\end{array}$ & $\begin{array}{l}\text { Moderate-to-severe } \\
\text { methimazole } \\
\text { for 3-4 months before } \\
\text { radioiodine therapy }\end{array}$ & $\begin{array}{l}\text { Linear accelerator/20Gy } 10 \\
\text { degrees anterior/ } \\
4 \times 4 \mathrm{~cm}\end{array}$ & $\begin{array}{l}\text { After } 12 \text { months, motility in } \\
\text { degrees, } \\
\text { proptosis, lid aperture, optic } \\
\text { neuropathy, diplopia }\end{array}$ \\
\hline $\begin{array}{l}\text { Kahaly et al., } \\
(2000)\end{array}$ & $\begin{array}{l}62 \\
A=181 \text { Gray/week } \\
20 \text { Gray/20 weeks } \\
B=221 \text { Gray/day } \\
10 \text { Gray/2 weeks } \\
C=222 \text { Gray/day } \\
20 \text { Gray/2 weeks }\end{array}$ & $\begin{array}{l}\text { Signs and symptoms with enlarged } \\
\text { extraocular eye muscles on magnetic } \\
\text { resonance imaging (MRI) }\end{array}$ & $\begin{array}{l}\text { Mild to moderate eye } \\
\text { disease, euthyroidism, } \\
\text { antithyroid drugs }\end{array}$ & $\begin{array}{l}\text { Linear accelerator/20Gy-10 } \\
\text { Gy/3 degrees anterior/ } \\
5 \times 6 \mathrm{~cm}\end{array}$ & $\begin{array}{l}\text { After } 12 \text { months, lid aperture, } \\
\text { proptosis, motility in degrees, } \\
\text { diplopia, intraocular pressure }\end{array}$ \\
\hline Ng et al., (2005) & $\begin{array}{l}16 \\
\mathrm{RT}+\mathrm{GC}: 8 \\
\mathrm{GC}: 8\end{array}$ & $\begin{array}{l}\text { Signs and symptoms with enlarged } \\
\text { extraocular eye muscles on } \\
\text { computed tomography or } \\
\text { magnetic resonance imaging (MRI) }\end{array}$ & $\begin{array}{l}\text { Moderate-to-severe } \\
\text { ophthalmopathy, } \\
\text { anti-thyroid drugs, } \\
\text { radioactive iodine, } \\
\text { thyroidectomy }\end{array}$ & $\begin{array}{l}\text { Linear accelerator/20Gy-10 } \\
\text { Gy/10 degrees anterior/ } \\
4 \times 4 \mathrm{~cm}\end{array}$ & $\begin{array}{l}\text { After } 12 \text { months, motility } \\
\text { in degrees, } \\
\text { proptosis, lid aperture }\end{array}$ \\
\hline $\begin{array}{l}\text { Bartalena et al., } \\
\text { (1983) }\end{array}$ & $\begin{array}{l}48 \\
R T+G C 36 \\
G C: 12\end{array}$ & $\begin{array}{l}\text { Signs and symptoms with enlarged } \\
\text { extraocular eye muscles }\end{array}$ & $\begin{array}{l}\text { Moderate-to-severe } \\
\text { ophthalmopathy, } \\
\text { anti-thyroid drugs, } \\
\text { radioactive iodine, } \\
\text { thyroidectomy }\end{array}$ & $\begin{array}{l}\text { Cobalt -60/20Gy-10 Gy/10 } \\
\text { degrees anterior/ } \\
4 \times 4 \mathrm{~cm}\end{array}$ & $\begin{array}{l}\text { After } 12 \text { months, } \\
\text { ophthalmic index, } \\
\text { proptosis, optic neuropathy }\end{array}$ \\
\hline $\begin{array}{l}\text { Gorman et al., } \\
\text { (2002) }\end{array}$ & $\begin{array}{l}42 \\
\text { RT:21 } \\
\text { NO RT:21 }\end{array}$ & $\begin{array}{l}\text { Signs and symptoms with enlarged } \\
\text { extraocular eye muscles on } \\
\text { computed tomography }\end{array}$ & $\begin{array}{l}\text { Mild to moderate } \\
\text { ophthalmopathy } \\
\text { anti-thyroid drugs, } \\
\text { radioactive iodine, } \\
\text { thyroidectomy }\end{array}$ & $\begin{array}{l}\text { Linear accelerator/20Gy-10 } \\
\text { Gy/10 degrees anterior/ } \\
4 \times 4 \mathrm{~cm}\end{array}$ & $\begin{array}{l}\text { After } 6 \text { months, motility } \\
\text { in degrees, } \\
\text { proptosis, lid aperture, } \\
\text { clinical activity scores }\end{array}$ \\
\hline $\begin{array}{l}\text { Prummel et al., } \\
\text { (1993) }\end{array}$ & $\begin{array}{l}56 \\
\text { RT:28 } \\
\text { GC: } 28\end{array}$ & $\begin{array}{l}\text { Signs and symptoms with enlarged } \\
\text { extraocular eye muscles }\end{array}$ & $\begin{array}{l}\text { Moderate } \\
\text { ophthalmopathy } \\
\text { anti-thyroid drugs, } \\
\text { radioactive iodine, } \\
\text { thyroidectomy }\end{array}$ & $\begin{array}{l}\text { Linear accelerator or cobalt } \\
-60 / 20 \mathrm{G}-10 \mathrm{~Gy} / 10 \text { degrees } \\
\text { anterior/ } \\
5 \times 5 \mathrm{~cm}\end{array}$ & $\begin{array}{l}\text { After } 6 \text { months, } \\
\text { eye score and a decrease in } \\
\text { eye-muscle volume }\end{array}$ \\
\hline $\begin{array}{l}\text { Mourits et al., } \\
(2000)\end{array}$ & $\begin{array}{l}60 \\
\text { RT: } 30 \\
\text { NO RT: } 30\end{array}$ & $\begin{array}{l}\text { Signs and symptoms with enlarged } \\
\text { extraocular eye muscles on coronal } \\
\text { computed tomography scan of the } \\
\text { orbits }\end{array}$ & $\begin{array}{l}\text { Moderate-to-severe } \\
\text { ophthalmopathy, } \\
\text { anti-thyroid drugs, } \\
\text { radioactive iodine, } \\
\text { thyroidectomy }\end{array}$ & $\begin{array}{l}\text { Linear accelerator/20Gy-10 } \\
\text { Gy/10 degrees anterior/ } \\
4 \times 4 \mathrm{~cm}\end{array}$ & $\begin{array}{l}\text { After } 6 \text { months, } \\
\text { eyelid aperture, proptosis, } \\
\text { eye movements, subjective } \\
\text { eye score, and clinical-activity }\end{array}$ \\
\hline
\end{tabular}

RT: radiation therapy; NO RT: no radiation therapy; GC: glucocorticoid; IV: intravenous; TSH: thyroid-stimulating hormone.

Table 2. Ocular parameters and results post treatment evaluated in randomized clinical trails

\begin{tabular}{|c|c|c|c|c|c|c|c|c|}
\hline Trial & $\begin{array}{c}\text { Prummel } \\
1993\end{array}$ & $\begin{array}{c}\text { Marcocci* }^{*} \\
2000\end{array}$ & $\begin{array}{c}\text { Bartalena } \\
1983\end{array}$ & $\begin{array}{c}\mathrm{Ng} \\
2005\end{array}$ & $\begin{array}{c}\text { Kahaly } \\
2000\end{array}$ & $\begin{array}{c}\text { Mourits } \\
2001\end{array}$ & $\begin{array}{c}\text { Prummel } \\
2004\end{array}$ & $\begin{array}{c}\text { Gorman } \\
2001\end{array}$ \\
\hline \multicolumn{9}{|l|}{ Parameter } \\
\hline Quality of life & 0 & 0 & 0 & 0 & 0 & 0 & $=$ & 0 \\
\hline Proptosis (mm) & $=$ & + & 0 & 0 & 0 & 0 & 0 & 0 \\
\hline Lid width (mm) & 0 & + & 0 & 0 & 0 & 0 & 0 & 0 \\
\hline Visual acuity & 0 & 0 & 0 & $=$ & $=$ & 0 & 0 & 0 \\
\hline Diplopia & 0 & $=$ & 0 & 0 & $=$ & + & + & $=$ \\
\hline Intraocular pressure & $=$ & $=$ & $=$ & 0 & 0 & 0 & 0 & 0 \\
\hline Optic neuropathy & 0 & + & + & 0 & 0 & 0 & 0 & 0 \\
\hline Ocular motility & + & + & + & + & $=$ & + & + & $=$ \\
\hline Clinical response & $=$ & + & + & + & $=$ & + & + & $=$ \\
\hline Cost & 0 & 0 & 0 & 0 & 0 & 0 & $=$ & 0 \\
\hline Side effects & - & - & + & $=$ & - & + & + & + \\
\hline
\end{tabular}

* = Marcocci trial + was used for RT 20 Gy plus IV glucocorticoid and 0 was used for RT 20 Gy plus oral glucocorticoid; += significant for radiotherapy 20 Gy arms with or without glucocorticoids when compared to the other treatment; -= significant for another treatment; $(=)=$ no difference between the arms of study; $0=$ no evaluation. 
Table 3. Description of the design, aim, question, results and conclusion of the studies included in this meta-analysis

\begin{tabular}{llll}
\hline Author Year & $\begin{array}{c}\text { Design /aim/ } \\
\text { study question }\end{array}$ & Results & Conclusions/comments
\end{tabular}

\begin{tabular}{ll}
\hline $\begin{array}{l}\text { Prummel et al., } \\
2004\end{array}$ & $\begin{array}{l}\text { Double-blind } \\
\text { randomized trial }\end{array}$ \\
& $\begin{array}{l}\text { To compared RT efficacy with sham } \\
\text { irradiation in mild ophthalmopathy }\end{array}$
\end{tabular}

Ng et al., $\quad$ Double-blind

2005 randomized trial

To assess the efficacy and safety of combined orbital irradiation and systemic steroids in the management of moderate-tosevere Graves' ophthalmopathy

Prummel et al., Double-blind

$1993 \quad$ randomized trial

Marcocci et al., Randomized trial

2001

Gorman et al., Prospective, randomized, internally $2001 \quad$ controlled, double-blind clinical trial

To evaluate the efficacy of radiotherapy for $\mathrm{GO}$

To assess the efficacy and safety of orbital radiotherapy combined with either oral (prednisone; starting dose, $100 \mathrm{mg} / \mathrm{d}$; withdrawal after 5 months) or IV (methylprednisolone; $15 \mathrm{mg} / \mathrm{kg}$ for four cycles and then $7.5 \mathrm{mg} / \mathrm{kg}$ for four cycles; each cycle consisted of two infusions on alternate days at 2-wk intervals) glucocorticoids

RT was successful in 23 of 44 (52\%) irradiated patients vs. 12 of 44 (27\%) sham-irradiated patients at 12 months after treatment (relative risk, $1.9 ; 95 \% \mathrm{Cl}, 1.1-3.4 ; P=0.02$ ). was effective in improving eye muscle motility and decreasing the severity of diplopia. Quality of life improved similarly in both groups. In the radiotherapy group there was less need for follow-up treatment; $66 \%$ vs. $84 \%$ of the patients needed further treatment $(P=0.049)$

Total eye score improved earlier in the SRT group, achieving statistical significance $(P<0.05)$ at as early as 4 weeks of follow-up. Improvement in ocular parameters was greater and led to a significantly greater reduction in total eye score than in the steroids group at weeks 16, 24, and 52. Maximum extra-ocular muscle thickness was significantly reduced in the steroids plus RT group only. No change was observed in proptosis in either group. No serious adverse effect was observed with the addition of orbital irradiation to steroid therapy

A successful outcome was observed in 14 prednisone-treated and in 13 RT patients. Responders to treatment (but not nonresponders) in both groups showed improvements in total and subjective eye score and a decrease in eye-muscle volume. Response to either treatment was due largely to changes in softtissue involvement and eye-muscle motility. Mean elevation in responders to radiotherapy increased from 18.5 degrees (95\% Cl $14.8-22.2)$ at baseline to 21.8 degrees $(18.6-25.0)$ at week twenty-four ( $p=0.003$ ), but did not change in prednisone responders. Side-effects were more frequent and severe during prednisone than during radiotherapy.

A significant reduction in proptosis (from $23.2 \pm 3.0$ to

$21.6 \pm 1.2 \mathrm{~mm}$ in the IV glucocorticoid group, $P<0.0001$; and

from $23 \pm 1.8$ to $21.7 \pm 1.8 \mathrm{~mm}$ in oral glucocorticoid group,

$P<0.0001$ ) and in lid width (from $13.3 \pm 2.5$ to $11.8 \pm 2.2 \mathrm{~mm}$, and from $13.6 \pm 2.0$ to $11.5 \pm 1.9 \mathrm{~mm}$, respectively; $P<0.001$ in both cases) occurred, with no difference between the two groups.

Diplopia significantly improved in both groups: it disappeared in 13 of $27(48.1 \%)$ IV glucocorticoid patients $(P<0.005)$ and in 12 of 33 (36.4\%) oral glucocorticoid patients $(P<0.03)$

No clinically or statistically significant difference between the treated and untreated orbit was observed in any of the main outcome measures at 6 months. At 12 months, muscle volume and proptosis improved slightly more in the orbit that was treated first

Response to therapy, defined as a significant amelioration of three objective parameters, was noted in $12 \mathrm{~A}(67 \%), 13 \mathrm{~B}$ (59\%), and 12 C (55\%) subjects (C vs. A, P 5 0.007). Ophthalmic symptoms and signs regressed most in group $A$; changes in lid fissure width were $21.5,20.5$, and $0 \mathrm{~mm}$ in the $A, B$, and $C$ groups, respectively ( $A$ vs. $C, P<0.005$ ), whereas changes in intraocular pressure (upgaze) were 23,11 , and $21.5 \mathrm{mmHg}$, respectively (A vs. B, P 5 0.002)

Patients treated by combined therapy, 12 (33\%) showed excellent responses, 14 (39\%) showed good responses, 9 (25\%) showed slight responses, and 1 (3\%) had no response. Treatment was more effective for soft tissue involvement, newly developed ophthalmoplegia, and optic neuropathy, while proptosis and longstanding ophthalmoplegia were less responsive

The qualitative treatment outcome was successful in 18 of $30(60 \%)$ irradiated patients versus nine of $29(31 \%)$ sham-irradiated patients at week 24 . This difference was caused by improvements in diplopia grade, but not by reduction of proptosis, nor of eyelid swelling
Tested the efficacy of external beam irradiation compared with sham-irradiation
RT is an effective treatment in mild ophthalmopathy. The improvement upon irradiation may not be associated with an increase in quality of life or a reduction in treatment costs

A combination of orbital RT and systemic steroids is well tolerated and more effective than steroids alone in the treatment of active moderate-to-severe Graves' ophthalmopathy. It achieves greater and more rapid improvement in soft tissue swelling, ocular motility, and visual acuity

RT and oral prednisone appear to be equally effective as initial treatment in patients with moderately severe Graves' ophthalmopathy. In view of its better tolerability, radiotherapy should be considered the treatment of first choice

High-dose IV glucocorticoid and oral glucocorticoid (associated with orbital radiotherapy) are effective in the management of severe Graves' ophthalmopathy, but the IV route seems to be more effective and better tolerated than the oral route and associated with a lower rate of side effects

This study was unable to demonstrate any beneficial therapeutic effect. The slight improvement noted in both orbits at 12 months may be the result of natural remission or of radiotherapy, but the changes are of marginal clinical significance

Patients with moderately severe $\mathrm{GO}$, similar response rates were observed for low and high Rx doses, but the $1 \mathrm{~Gy} /$ week protocol was more effective and better tolerated than the short arm regimens

The study indicates that both orbital RT combined with systemic methylprednisolone treatment and systemic methylprednisolone therapy alone are valuable methods of treatment for Graves' ophthalmopathy, but the combined therapy proved to be more effective

In these patients with moderately severe Graves' ophthalmopathy, radiotherapy should be used only to treat motility impairment 


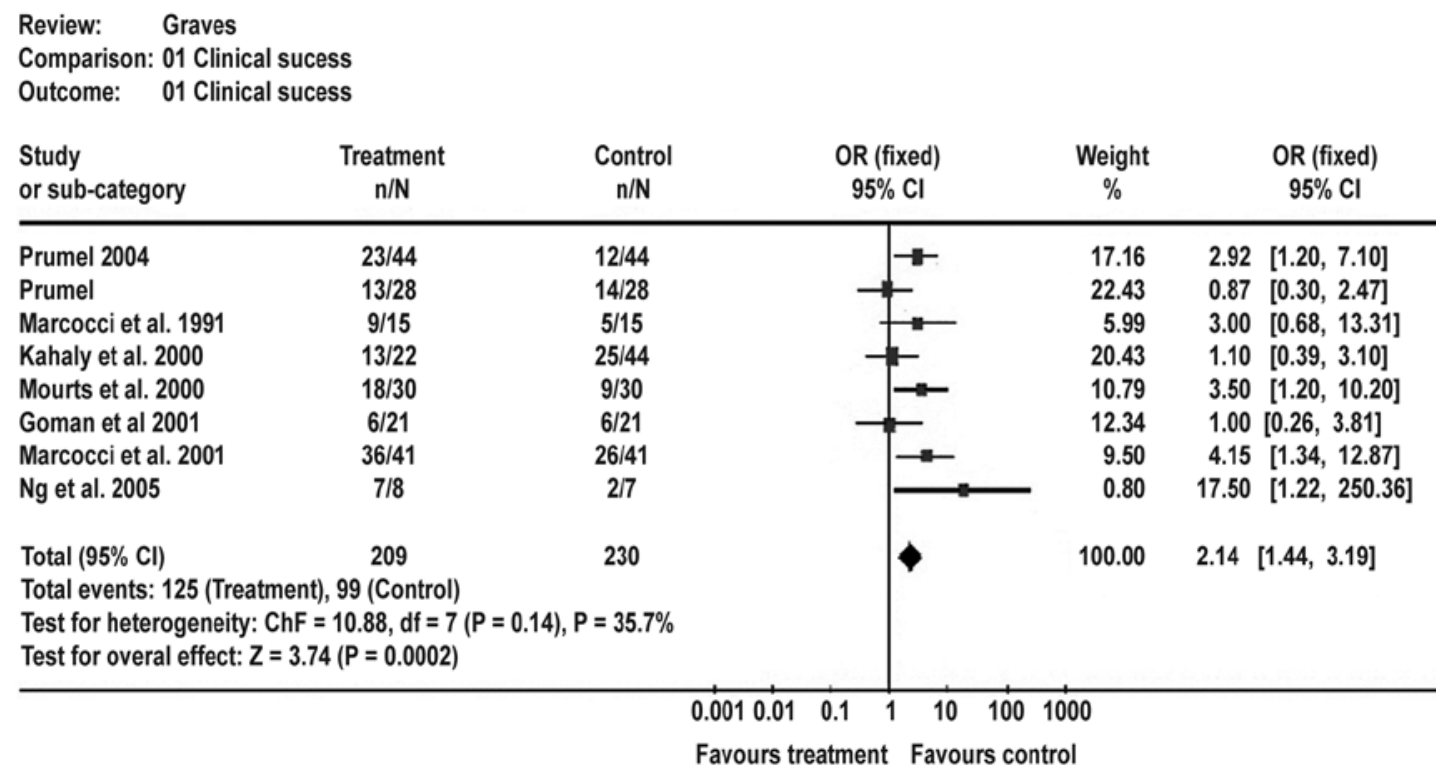

OR: odds ratio.

Figure 2. Treatment response comparing radiation therapy 20 Gy to other treatments in the randomized controlled trial.

The overall odds ratio suggests that there is difference between RT 20 Gy arms and no RT 20 Gy arms in terms of response to treatment rate with $p$ value 0.003 , as shown in table 4 .

\section{RADIOTHERAPY PLUS GLUCOCORTICOID VERSUS GLUCOCORTICOID}

One randomized study ${ }^{(16)}$ (15 patients) compared the efficacy of combined orbital irradiation and systemic steroids in the management of moderate-to-severe Graves' ophthalmopathy. The odds ratio for this trial was of 17.50 with a $95 \%$ confidence interval of 1.85 to 250 . The test for heterogeneity was not statistically significant with $p$ value 0.42 , which indicates that the pooling of the data was valid. The overall odds ratio suggests that there is difference between RT 20 Gy arms and glucocorticoid arms in terms of response to treatment rate with $p$ value 0.04 , as demonstrated in the table 4 .

\section{RADIOTHERAPY PLUS IV GLUCOCORTICOID VERSUS RADIOTHERAPY PLUS ORAL GLUCOCORTICOID}

One study ${ }^{(14)}$ (82 patients) compared the efficacy radiotherapy plus IV glucocorticoid versus radiotherapy plus oral glucocorticoid. The odds ratio of this study was 4.15 with 95\% confidence interval of 1.34 to 12.87 , suggesting that there is difference between radiotherapy plus IV glucocorticoid versus radiotherapy plus oral glucocorticoid in terms of response to treatment with $p$ value 0.01 , shown in table 4.

\section{RADIOTHERAPY WITH 20 Gy VERSUS OtheR FRACTIONATIONS}

One study ${ }^{(12)}$ (66 patients) compared the efficacy of radiotherapy with a total dose of $20 \mathrm{~Gy}$ versus others fractionations. The odds ratio of this study was 1.10 with $95 \%$ confidence interval of 0.39 to 3.10 , suggesting that there is no difference between radiotherapy with a total dose of 20 Gy versus others fractionations for response to treatment, as demonstrated in table 4.

\section{QUALITY OF LIFE AND COSTS}

One study of Prummel et al., ${ }^{(15)}$ (88 patients) evaluated the quality of life and costs and did not evidence differences in quality of life or costs between patients submitted to radiotherapy versus sham radiotherapy for $\mathrm{GO}$.

\section{RADIOTHERAPY VERSUS GLUCOCORTICOID}

One study ${ }^{(8)}$ (56 patients) compared the efficacy of radiotherapy with a total dose of 20 Gy versus glucocorticoid. The odds ratio of this study was 0.87 with $95 \%$ confidence interval of 0.30 to 2.87 , suggesting that there is no difference between radiotherapy with a total dose of $20 \mathrm{~Gy}$ versus glucocorticoid for response to treatment, as described in table 4.

\section{RADIOTHERAPY PLUS IV GLUCOCORTICOID VERSUS RADIOTHERAPY ALONE}

One study ${ }^{(13)}$ (30 patients) compared the efficacy of radiotherapy plus IV glucocorticoid versus radiotherapy alone. The odds ratio this study was 3 with $95 \%$ confidence interval of 0.68 to 13.31, suggesting that there is no difference between radiotherapy with a total dose of 20 Gy plus glucocorticoid versus radiotherapy alone for response to treatment, as shown in table 4.

\section{Quality OF STUdies}

The median of the quality scores was of 4 points (in a 5-point scale), with none study scoring $0,1,2$, or 3 . There was complete agreement in scoring by the two assessors. The quality scores were high, five trials scored 5 points ${ }^{(8-10,15,16)}$ and three trials scored 4 points in the Jada scale. This fact occurred because of the importance placed on blinding in the scoring system, and the inherent difficulty in blinding a treatment such as radiation, as shown in the table 3 .

\section{Evaluation of publication Bias}

The funnel plot of the log ORs versus the inverse of their variances of the individual studies is displayed in figure 3. The plot formed a very distinct funnel shape with the log ORs evenly distributed around the meta-analysis OR regardless the study variance. Therefore, there was no indication of an asymmetry in the study findings by the variance or size of the studies and, thus, little evidence for publication bias.

\section{DISCUSSION}

External radiotherapy has been used for $\mathrm{GO}$ for around 60 years and it still represents a mainstay in the management of the disease ${ }^{(23)}$. The rationale for the use of radiotherapy for $\mathrm{GO}$ resides both in its 
Table 4. Odds ratio calculated according to the response to treatment for the trials included in this meta-analysis

\section{Estimated OR $(95 \% \mathrm{Cl})$, p value}

Response to treatment $(n=439)$

RT 20 Gy vs sham RT $(n=190)$

Prummel et al., 2004(15)

Mourits et al., 2000 ${ }^{(9)}$

Gorman et al., 2001(10)

RT 20 Gy plus glucocorticoid vs

glucocorticoid ( $n=15$ )

$\mathrm{Ng}$ et al., 2005(16)

RT 20 Gy IVGC vs RT ORGC * $(n=82)$

Marcocci et al., 2001 $1^{(14)}$

RT 20 Gy vs glucocorticoid ( $n=56$ )

Prummel et al., 1993 ${ }^{(8)}$

RT 20 Gy vs Low dose RT $(n=66)$

Kahaly et al., 2000(12)

RT 20 Gy plus glucocorticoid vs

RT 20 Gy $(n=30)$

Marcocci et al., 1991(13)

$\mathrm{OR}=$ odds ratio; $\mathrm{Cl}=$ confidence interval; $\mathrm{NR}=$ not reported; $\mathrm{RT}=$ radiotherapy.

${ }^{*}=$ IV methylprednisoloneacetate (IVGC) or oral prednisone (ORGC).

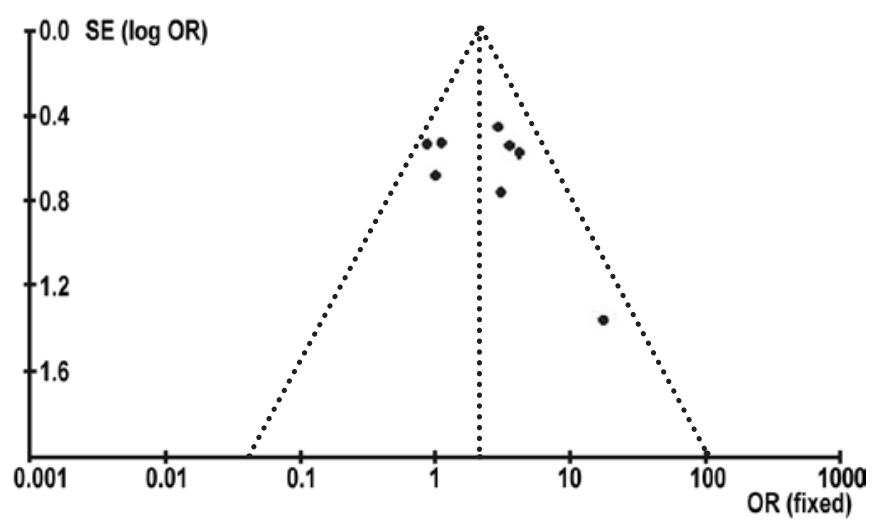

SE: size effect; OR: odds ratio.

Figure 3. Funnel plot for response to treatment using radiotherapy for Graves' ophthalmopathy.

nonspecific anti-inflammatory effect and in the high radio sensitivity of lymphocytes infiltrating the orbital space ${ }^{(24)}$. Lymphocytes are generally suppressed with relatively low doses of radiation, and the helper/suppressor T lymphocyte ratio is also altered by radiotherapy(23). In addition, radiotherapy might also reduce glycosaminoglycans production by orbital fibroblasts ${ }^{(25)}$. Whether the reported effectiveness of orbital radiotherapy in $\mathrm{GO}$ is related either to its nonspecific anti-inflammatory action, or to specific immunosuppressive effects, both need to be clarified. Our review of papers published between 1983 and 2006 showed that positive results were obtained using RT. According to most studies, orbital radiotherapy is especially effective on soft tissue inflammatory changes and recent extraocular muscle involvement, producing improvement in the ocular parameters as visual acuity, diplopia, proptosis, lid width, ocular motility and optic neuropathy, but without any benefit on intraocular pressure. It should be mentioned that all studies were randomized, controlled and of high quality. The latest 5 years have witnessed important discussions on the role of orbital radiotherapy, in particular questioning its effectiveness and safety ${ }^{(26-32)}$.
Most authors agree that orbital radiotherapy is a safe procedure. If the technique of radiation is correct, it seems not to increase the risk of cataract and retinopathy, except for patients with diabetic and hypertensive retinopathy ${ }^{(33,34)}$. The two latter conditions, especially if associated, should be considered as relative contraindications to orbital radiotherapy, in particular when signs of retinopathy are present before irradiation. It is worth noting that, even after a very long follow-up, orbital radiotherapy does not seem to bear a risk of radiation-induced tumors ${ }^{(35-40)}$. Thus, the safety of orbital radiotherapy is not a major matter of argument, but there is a controversy about its real effectiveness. This debate has been revitalized by a randomized, placebo-controlled, double-blind study from the Mayo Clinic ${ }^{(10)}$. In the original experimental design of this study, only one orbit of 42 patients with moderately severe GO was irradiated, whereas the contralateral orbit served as an internal control. A detailed analysis of objective measures was provided; leading the authors to conclude that orbital radiotherapy is ineffective and therefore, should not be offered to GO patients ${ }^{(10)}$. Although Gorman et al. should be congratulated on the major effort they made, our point about this study is that it has some structural errors.

One of them was the fact that a lot of patients had a longstanding ophthalmopathy and had been already treated before, apparently not well succeeded, by systemic glucocorticoids ${ }^{(10)}$. The second one involves timing of therapy, and the therapeutic goals of orbital radiation therapy. The authors in their study included patients between 0.2 and 16 years, with a median of 1.3 years with onset from the eye symptoms. The authors made no attempt to treat patients in the active progressive phase of thyroid eye disease. This phase disease is characterized by infiltration of the extra-ocular muscles with lymphocytes, and it is the prime radiation sensitive period. Patients who do not respond to glucocorticoids are unlikely to show any benefit from orbital radiotherapy. In addition, the observation that the untreated orbit did not show any improvement or worsening during the 6-months period of further observation suggesting that enrolled patients had stable, non progressive, i.e. inactive ("burnt-out") eye disease. The third vital error was the stated goal of orbital radiation. In many institutions the stated goal of therapy is to halt or reverse severe progressive thyroid ophthalmopathy. The author's therapeutic objectives of treating patients who had chronic fibrotic thyroid ophthalmopathy established were unclear. This article seemed to evaluate if radiation therapy reversed such findings as orbital volume in patients with chronic thyroid ophthalmopathy. Our final concern about this article was the unusual port design for radiation therapy. This design may be useful as a research data, on the other hand, being human studies it can be considered as worrisome. Treating with their wedge pair field design to spare the contralateral eye, the authors increased the volume of normal tissue significantly, including the frontal lobes and parotid glands, exposed to radiation compared to the standard opposed lateral fields. Although the risks of a secondary malignancy in the treatment of those patients are slight, increasing the volume would be expected to increase this risk. But the long-term effects of a low dose radiation in a larger volume of the frontal lobe may have subtle effects in the higher brain functions.

What did the other randomized controlled trials tell us about the efficacy of orbital radiotherapy for GO? In 1993, a randomized double-blind trial of prednisone vs. orbital radiotherapy in patients with moderately severe $\mathrm{GO}^{(8)}$ demonstrated that the proportion of responders in prednisone-treated (14 of $28,50 \%)$ and irradiated (13 of $28,46 \%)$ patients (18\%) was similar. That time, there were no doubts that glucocorticoid was an effective treatment for $\mathrm{GO}$. However, from this study through non direct comparison RT has started to be also considered effective. In addition, the study above also demonstrated a decrease in the eye muscle volume, as assessed by the eye muscle score $^{(8)}$. In 2000 those data were confirmed for a double-blind ran- 
domized study which included 60 patients with moderately severe GO who were submitted to either orbital radiotherapy or sham-irradiation ${ }^{(9)}$. The qualitative treatment outcome was successful in $60 \%$ of irradiated patients and in only $31 \%$ of sham irradiated patients ${ }^{(9)}$. Improvement was mainly confined to eye movements; it should also be noted that $25 \%$ of irradiated patients were saved from additional strabismus surgery ${ }^{(9)}$. In 2004 a new important information ${ }^{(15)}$ about the use of orbital radiotherapy was provided for GO by Prummel et al. This double-blind, randomized clinical trial was the first to address the question of whether orbital radiotherapy has a place in the management of nonsevere GO. Based on the evaluation of changes in major and minor criteria prespecified, primary therapeutic outcome was successful in 52\% of irradiated patients and in only $27 \%$ of sham-irradiated patients ${ }^{(15)}$, with improvement in the eye muscle function and diplopia. It should also be noted that the orbital radiotherapy was not associated with a greater improvement of quality of life, compared to sham irradiation ${ }^{(15)}$. This paper also provides valuable information that orbital radiotherapy did not prevent progression to more severe expressions in about 15\% of the patients. The reason why the severe forms of GO develop is still unclear nowadays, but it seems that environmental factors play a decisive role in this progression $^{(40)}$. Thus, if the study by Prummel et al. ${ }^{(15)}$, lends further support to the concept that orbital radiotherapy is in general an effective treatment for $\mathrm{GO}$, it also suggests that the commonly adopted policy of "wait-and-see" in cases of mild GO should be maintained, including the cost/benefit considerations. At present, most centers utilize linear accelerators delivering 4-6 megavolts and use a 4 × 4-cm lateral field slightly angled posteriorly to avoid as much as possible irradiation to the contralateral lens. The use of higher energy sources has not proven to be particularly advantageous. The most common delivered dose is 20 grays (Gy) per eye ${ }^{(30)}$; this cumulative dose is usually fractionated in 10 daily doses over a 2-week period to reduce the cataractogenic effect of irradiation ${ }^{(27)}$. The importance of dose was evaluated by Kahaly et al., ${ }^{(12)}$, using different radiation doses. It reported that a therapeutic scheme of 1 Gy per week over a 20-week period was equally effective and possibly better tolerated than the classical 2-week scheme. The use of higher cumulative doses of radiation (30 Gy vs. 20 Gy) does not produce any increase in the effectiveness of treatment ${ }^{(41)}$. Irrespective of small differences observed using low-dose vs. high-dose radiotherapy, beneficial effects of radiotherapy were observed in all the three groups of patients in 55 to $67 \%$ of cases. In summary, what is the message to the reader, based on the present systematic review?

\section{CONCLUSION}

Our data has shown that orbital radiotherapy still has an important role in the management of GO. Although there are a lot of available studies in the literature, they have a limited impact owing to selection bias and lack of an appropriate ophthalmological assessment. In the era of evidence-based medicine it cannot be denied that six of eight randomized and controlled studies showed that orbital radiotherapy is effective on GO, especially on extraocular muscle involvement. Orbital radiotherapy, in burning out eye disease, can also make eye muscle and/or eyelid corrective surgery possible in earlier stages. The effectiveness of orbital radiotherapy can be increased by the synergistic interaction with glucocorticoids. Orbital radiotherapy should still be offered as a valid therapeutic option to patients with moderate to severe GO. The selection of patients is fundamental, because patients with inactive ("burnt-out") GO are unlikely to respond to irradiation (as well as to glucocorticoids). The use of orbital radiotherapy in the early stage of the disease (possibly less than 1 year from the onset) is recommended. The real efficacy of orbital radiotherapy should come from well-designed, multicenter, randomized and controlled studies enrolling a large number of patients.

\section{REFERENCES}

1. Brown J, Coburn JW, Wigod RA, Hiss JM Jr, Dowling JT. Adrenal steroid therapy of severe infiltrative ophthalmopathy of Graves' disease. Am J Med. 1963;34:786-95.

2. Cortisone in exophthalmos: report on a therapeutic trial of cortisone and corticotrophin (ACTH) in exophthalmos and exophthalmic ophthalmoplegia by a panel appointed by the Medical Research Council. Lancet. 1955;268(6853):6-9.

3. Bartalena L, Marcocci C, Bogazzi F, Panicucci M, Lepri A, Pinchera A. Use of corticosteroids to prevent progression of Graves' ophthalmopathy after radioiodine therapy for hyperthyroidism. N Engl J Med. 1989;321(20):1349-52. Comment in: N Engl J Med. 1989;321(20):1403-5; N Engl J Med. 1990;322(15):1088-9.

4. Bartalena L, Marcocci C, Bogazzi F, Manetti L, Tanda M, Dell'Unto E, et al. Relation between therapy for hyperthyroidism and the course of Graves' ophthalmopathy. N Engl J Med. 1998;338(2):73-8. Comment in: N Engl J Med. 1998;338(2):121-2; N Engl J Med. 1998;338(21):1546-7; ACP J Club. 1998;128(3):71.

5. Trobe JD, Glaser JS, Laflamme P. Dysthyroid optic neuropathy. Clinical profile and rationale for management. Arch Ophthalmol. 1978;96(7):1199-209.

6. Marquez SD, Lum BL, McDougall IR, Katkuri S, Levin PS, MacManus M, et al. Long-term results of irradiation for patients with progressive Graves' ophthalmopathy. Int J Radiat Oncol Biol Phys. 2001;51(3):766-74.

7. Wakelkamp IM, Tan H, Saeed P, Schlingemann RO, Verbraak FD, Blank LE, et al. Orbital irradiation for Graves' ophthalmopathy: Is it safe? A long-term follow-up study. Ophthalmology. 2004;111(8):1557-62.

8. Prummel MF, Mourits MP, Blank L, Berghout A, Koornneef L, Wiersinga WM. Randomized double-blind trial of prednisone versus radiotherapy in Graves' ophthalmopathy. Lancet. 1993;342(8877):949-54. Comment in: Lancet. 1993;342(8877):941.

9. Mourits MP, van Kempen-Harteveld ML, Garcia MB, Koppeschaar HP, Tick L, Terwee CB. Radiotherapy for Graves' orbitopathy: randomised placebo-controlled study. Lancet. 2000;355(9214):1505-9.

10. Gorman CA, Garrity JA, Fatourechi V, Bahn RS, Petersen IA, Stafford SL, et al. A prospective, randomized, double-blind, placebo-controlled study of orbital radiotherapy for Graves' ophthalmopathy. Ophthalmology. 2001;108(9):1523-34.

11. Donaldson SS, Bagshaw MA, Kriss JP. Supervoltage orbital radiotherapy for Graves' ophthalmopathy. J Clin Endocrinol Metab. 1973;37(2):276-85.

12. Kahaly GJ, Rosler H-P, Pitz S, Hommel G Low-versus highdose adiotherapy for Graves' ophthalmopathy: a randomized, single blind trial. J Clin Endocrinol Metab. 2000; 85(1):102-8.

13. Marcocci C, Bartalena L, Bogazzi F, Bruno-Bossio G, Lepri A, Pinchera A. Orbital radiotherapy combined with high dose systemic glucocorticoids for Graves' ophthalmopathy is more effective than radiotherapy alone: results of a prospective randomized study. J Endocrinol Invest. 1991;14(10): 853-60.

14. Marcocci C, Bartalena L, Tanda ML, Manetti L, Dell'Unto E, Rocchi R, et al. Comparison of the effectiveness and tolerability of intravenous or oral glucocorticoids associated with orbital radiotherapy in the management of severe Graves' ophthalmopathy: results of a prospective, single-blind, randomized study. J Clin Endocrinol Metab. 2001;86(8):3562-7.

15. Prummel MF, Terwee CB, Gerding MN, Baldeschi L, Mourits MP, Blank L, et al. A randomized controlled trial of orbital radiotherapy versus sham irradiation in patients with mild Graves' ophthalmopathy. J Clin Endocrinol Metab. 2004;89(1):15-20.

16. Ng CM, Yuen HK, Choi KL, Chan MK, Yuen KT, Ng YW, et al. Combined orbital irradiation and systemic steroids compared with systemic steroids alone in the management of moderate-to-severe Graves' ophthalmopathy: a preliminary study. Hong Kong Med J. 2005; 11(5):322-30.

17. Bartalena L, Marcocci C, Chiovato L, Laddaga M, Lepri G, Andreani D, et al. Orbital cobalt irradiation combined with systemic corticosteroid for Graves' ophthalmopathy: comparison with systemic corticosteroids alone. J Clin Endocrinol Metab. 1983; 56(6):1139-44

18. Ohtsuka K, Sato A, Kawaguchi S, Hashimoto M, Suzuki Y. Effect of steroid pulse therapy with and without radiotherapy on Graves' ophthalmopathy. Am J Ophthalmol. 2003; 135(3):285-90

19. Moher D, Cook DJ, Eastwood S, Olkin I, Rennie D, Stroup DF. Improving the quality of reports of meta-analyses of randomised controlled trials: the QUOROM statement. Quality of Reporting of Meta-analyses. Lancet. 1999;354(9193):1896-900. Comment in: Lancet. 2005;366(9503):2081-2; author reply 2083-6; Lancet. 2000;355(9205):756-7; Lancet. 1999;354(9193):1834-5.

20. Clarke M, Oxman AD, editors. Analysing and presenting results. Cochrane Reviewers Handbook, 4.1.6 [updated January 2003], Section 8. In The Cochrane Library. Oxford: Update Software; 2003.

21. DerSimonian R, Laird N. Meta-analysis in clinical trials. Control Clin Trials. 1986;7(3): 177-88.

22. Jadad AR, Moore RA, Carroll D. Assessing the quality of reports of randomized clinical trials: is blinding necessary? Control Clin Trials. 1996;17(1):1-12.

23. Pinchera A, Bartalena L, Chiovato L, Marcocci C. Radiotherapy of Graves'ophthalmopathy. In: Gorman CA, Waller RR, Dyer JA, editors. The eye and orbit in thyroid disease. New York: Raven Press; 1984. p.301-16.

24. Bartalena L, Marcocci C, Manetti L, Tanda ML, Dell'Unto E, Rocchi R, et al. A Orbital radiotherapy for Graves' ophthalmopathy. Thyroid. 1998;8(5):439-41. 
25. Kahaly G, Beyer J. Immunosuppressant therapy of thyroid eye disease. Klin Wochenschr. 1988;66(21):1049-59.

26. Bartley GB, Gorman CA. The Mayo orbital radiotherapy for Graves' ophthalmopathy (ORGO) study: lessons learned. Ophthal Plast Reconstr Surg. 2002;18(13):170-2.

27. Kazim M. Radiotherapy for Graves orbitopathy: the Columbia University experience. Ophthal Plast Reconstr Surg. 2002;18(13):173-4.

28. Wiersinga WM. Perspective. Part III. Retrobulbar irradiation in Graves orbitopathy: the Dutch experience. Ophthal Plast Reconstr Surg. 2002;18(13):175-6.

29. Perros P, Krassas GE. Orbital irradiation for thyroid-associated orbitopathy: conventional dose, low dose or no dose? Clin Endocrinol (Oxf). 2002;56(6):689-91.

30. Cockerham KP, Kennerdell JS. Does radiotherapy have a role in the management of thyroid orbitopathy? View 1. Br J Ophthalmol. 2002;86(1):102-4. Comment in: Br J Ophthalmol. 2002;86(1):106-7; Br J Ophthalmol. 2002;86(1):104-6.

31. Mourits MP. Does radiotherapy have a role in the management of thyroid orbitopathy? View 2. Br J Ophthalmol. 2002;86(1):104-6. Comment In: Br J Ophthalmol. 2002; 86(1):106-7. Comment on: Br J Ophthalmol. 2002;86(1):102-4

32. Bartalena L, Marcocci C, Gorman CA, Wiersinga WM, Pinchera A Orbital radiotherapy for Graves' ophthalmopathy: useful or useless? Safe or dangerous? J Endocrinol Invest. 2003;26(1):5-18

33. Miller ML, Goldberg SH, Bullock JD. Radiation retinopathy after standard radiotherapy for thyroid-related ophthalmopathy. Am J Ophthalmol. 1991;112(5):600-1.

34. Kinyoun JL, Kalina RE, Brower SA, Mills RP, Johnson RH. Radiation retinopathy after orbital irradiation for Graves' ophthalmopathy. Arch Ophthalmol. 1984;102(10): $1473-6$.

35. Marcocci C, Bartalena L, Rocchi R, Marino M, Menconi F, Morabito E, et al. A Long-term safety of orbital radiotherapy for Graves' ophthalmopathy. J Clin Endocrinol Metab. 2003:88(8):3561-6.

36. Gorman CA, Garrity JA, Fatourechi V, Bahs RS, Petersen IA, Stafford SL, et al. The aftermath of orbital radiotherapy for Graves' ophthalmopathy. Ophthalmology. 2002; 109(11):2100-7.

37. Marquez SD, Lum BL, McDougall IR, Katkuri S, Levin PS, MacManus PS, et al. Long-term results of irradiation for patients with Graves' ophthalmopathy. Int J Radiat Oncol Biol Phys. 2001;51(3):766-74.

38. Schaefer U, Hesselmann S, Micke O, Schueller P, Bruns F, Palma C, et al. A long-term follow-up study after retro-orbital irradiation for Graves' ophthalmopathy. Int J Radiat Oncol Biol Phys. 2002;52(1):192-7.

39. Bartalena L. Orbital radiation therapy and Graves' ophthalmopathy. Ophthalmology. 2003;110(3):452-3.

40. Marcocci C, Bartalena L, Bruno-Bossio G, Vanni G, Cartei F, Bogazzi F, et al. A Orbital radiotherapy in the treatmentof endocrine ophthalmopathy: when and why? In: Kahaly G, editor. Endocrine ophthalmopathy: molecular, immunological and clinical aspects. Basel; Kager; 1993. p.131-41.

41. Petersen IA, Kriss JP, McDougall IR, Donaldson SS. Prognostic factors in the radiotherapy if Graves' ophthalmopathy. Int J Radiat Oncol Biol Phys. 1990;19(2):259-64. 